\title{
Synergistic Antibacterial Effect of Casein-AgNPs Combined with Tigecycline against Acinetobacter baumannii
}

\author{
Yu-Hsuan Chen ${ }^{1}$, Wei-Hsun Wang ${ }^{2,3,4,5}$, Sheng-Hui Lin ${ }^{6,7}$, Yuan-Ting Yang-Wang ${ }^{8}$, Sung-Pin Tseng ${ }^{9}$, \\ Chi-Sheng Chien ${ }^{6,10, *}$ and Chi-Jen Shih $8,11,12, *$
}

1 School of Pharmacy, College of Pharmacy, Kaohsiung Medical University, Kaohsiung 807, Taiwan; ushen80118@gmail.com

2 Department of Orthopedic Surgery, Changhua Christian Hospital, Changhua 500, Taiwan; wangweihsun@gmail.com

3 School of Medicine, Kaohsiung Medical University, Kaohsiung 807, Taiwan

4 Department of Medical Imaging and Radiology, Shu-Zen Junior College of Medicine and Management, Kaohsiung 821, Taiwan

5 Department of Golden-Ager Industry Management, Chaoyang University of Technology, Taichung 413, Taiwan

6 Department of Orthopedics, Chi Mei Medical Center, Tainan 710, Taiwan; danteslin@gmail.com

7 Department of Leisure and Sports Management, Far East University, Tainan 744, Taiwan

8 Department of Fragrance and Cosmetic Science, College of Pharmacy, Kaohsiung Medical University, Kaohsiung 807, Taiwan; kmu102012062@gmail.com

9 Department of Medical Laboratory Science and Biotechnology, College of Health Science, Kaohsiung Medical University, Kaohsiung 807, Taiwan; tsengsp@kmu.edu.tw

check for updates

Citation: Chen, Y.-H.; Wang, W.-H.; Lin, S.-H.; Yang-Wang, Y.-T.; Tseng,

S.-P.; Chien, C.-S.; Shih, C.-J.

Synergistic Antibacterial Effect of

Casein-AgNPs Combined with

Tigecycline against Acinetobacter

baumannii. Polymers 2021, 13, 1529.

https://doi.org/10.3390/polym

13091529

Academic Editor: Florian J. Stadler

Received: 7 April 2021

Accepted: 5 May 2021

Published: 10 May 2021

Publisher's Note: MDPI stays neutral with regard to jurisdictional claims in published maps and institutional affiliations.

Copyright: (c) 2021 by the authors. Licensee MDPI, Basel, Switzerland. This article is an open access article distributed under the terms and conditions of the Creative Commons Attribution (CC BY) license (https:// creativecommons.org/licenses/by/ $4.0 /)$.
10 Department of Electrical Engineering, Southern Taiwan University of Science and Technology, Tainan 710, Taiwan

11 Department of Medical Research, Kaohsiung Medical University Hospital, Kaohsiung 807, Taiwan

12 Drug Development and Value Creation Research Center, Kaohsiung Medical University, Kaohsiung 807, Taiwan

* $\quad$ Correspondence: jannie.gissing@msa.hinet.net (C.-S.C.); cjshih@kmu.edu.tw (C.-J.S.)

\begin{abstract}
Acinetobacter baumannii (A. baumannii) is a common and challenging pathogen of nosocomial infections, due to its ability to survive on inanimate objects, desiccation tolerance, and resistance to disinfectants. In this study, we investigated an antibacterial strategy to combat $A$. baumannii via the combination of antibiotics and silver protein. This strategy used a functional platform consisting of silver nanoparticles (AgNPs) resurrected from silver-based calcium thiophosphate (SSCP) through casein and arginine. Then, the silver protein was combined with tigecycline, the first drug in glycylcycline antibiotic, to synergistically inhibit the viability of $A$. baumannii. The synergistic antibacterial activity was confirmed by the 96 -well checkerboard method to determine their minimum inhibitory concentrations (MIC) and calculated for the combination index (CI). The MIC of the combination of silver protein and tigecycline $(0.31 \mathrm{mg} / \mathrm{mL}, 0.16 \mu \mathrm{g} / \mathrm{mL})$ was significantly lower than that of the individual MIC, and the CI was 0.59 , which indicates a synergistic effect. Consequently, we integrated the detailed synergistic antibacterial properties when silver protein was combined with tigecycline. The result could make for a promising approach for the treatment of A. baumannii.
\end{abstract}

Keywords: synergistic antibacterial effect; AgNP; tigecycline; A. baumannii; silver protein

\section{Introduction}

Infections from common pathogens, such as Staphylococcus aureus, Pseudomonas aeruginosa and Acinetobacter baumannii, have resulted in difficulties [1,2]. Infectious patients may extend their inpatient days, require more medical resources, and increase the economic burden [3]. Among such pathogens, A. baumannii is mostly acquired within health-care facilities. Due to its ability to survive on inanimate objects, desiccation tolerance, and 
resistance to disinfectants, $A$. baumannii has become a global medical challenge [4,5]. However, the available antibiotics are now less efficacious, and the options for treatment are limited [6,7].

Tigecycline is considered to be a last-resort antibiotic with broad-spectrum activities against many Gram-positive bacteria, Gram-negative bacteria, anaerobes, and even drugresistant pathogens [8,9]. The dosage of tigecycline has been increasing because of the higher incidence of infection that does not respond to first-line antibiotics. Tigecycline consists of a glycylcycline structure that interacts with the bacterial $30 \mathrm{~S}$ ribosome subunit to inhibit bacterial protein synthesis. Presently, to combat A. baumannii infection, a practical therapy has been used combining tigecycline and other antibiotics, such as colistin, amikacin, levofloxacin, rifampicin, and so on [6].

However, combination therapies may cause several problems of overuse and abuse of antibiotics, and we propose the AgNPs combining with tigecycline as alternative antibacterial agents $[8,10]$. Therefore, a current antibacterial strategy is to develop a combination of antibacterial materials and antibiotics to combat pathogens. Metallic ions and metal nanoparticles are considered therapeutic agents, such as $\mathrm{Ag}^{+}, \mathrm{Cu}^{2+}, \mathrm{Cu}^{+}$, and $\mathrm{Au}^{2+}[11,12]$. Among these, silver nanoparticles (AgNPs) are well known for their outstanding broadspectrum antibacterial ability. In terms of the antibacterial mechanism, AgNPs contact the bacterial membrane and then damage the cell wall. AgNPs and Ag ions entering bacterial cells may increase reactive oxygen species (ROS) production and block the electron transport chain and eventually inhibit the synthesis of ATP [13]. However, the agglomeration of AgNPs would lose their nanosized characteristics and decrease antibacterial ability.

The green synthesis of nanoparticles has been considered to be a cost-effective, environmentally friendly, and lower-toxicity method compared to other chemical synthesis methods. Previous studies have investigated enzymes [14], bacteria [14], proteins [15], and plant extracts [16-18] as green precursors to prepare nanoparticles. There are some bio-based resources to maintain stabilized AgNPs reagent, such as plant extracts [16-21] and protein. Various proteins have been successfully used as carriers with advantages of preventing chemical degradation, increasing bioavailability, and controlling delivery [16,22-24]. Here, we investigated casein presenting a stabilizing effect on the AgNPs, and arginine possessing high affinity towards silver ions.

Therefore, AgNPs might be a potent antibacterial agent in combination with antibiotics for enhancing synergistic effects $[25,26]$. Pajares-Chamorro et al. demonstrated that silver-containing materials combined with antibiotics showed antibacterial efficacy through electron microscopy observation [27]. However, the bacterial growth kinetics in the $24 \mathrm{~h}$ following application of this combination have been less well investigated in previous works and did not demonstrate a combinatorial relationship. Tigecycline has been considered a last-line antibiotic against drug-resistant bacteria [28]. Moreover, the synergistic antibacterial activity of tigecycline combined with casein-AgNPs has yet to be studied.

In this study, we focused on the combination of silver protein with tigecycline and their synergistic effect against A. baumannii. AgNPs were based on casein from silver-containing silica-based calcium phosphate (SSCP) with a 1\% Ag molar ratio. Casein and arginine inspire AgNPs from SSCP as green synthesis. Casein could inspire silver nanoparticles to release from SSCP and stabilize as colloid. Then, arginine combining with casein-AgNPs increase the release of silver, because arginine has the highest affinity towards silver ions. To characterize the morphology of AgNPs, they were confirmed by TEM images and UV-visible spectroscopy. The size and distribution of the AgNPs were measured with at least 30 particles to obtain representative data. Furthermore, casein-AgNPs combined with tigecycline was investigated as a potent candidate for infection treatment. To evaluate the synergistic antibacterial efficacy of this combination, the checkerboard method was used to obtain their combination index $(\mathrm{CI})$ values. Then, interactions related to time-kill kinetic curves and colony-forming assays were used to determine the minimum inhibition concentration (MIC) and the minimum bactericidal concentration (MBC). Furthermore, we proposed an ecofriendly approach to prepare casein-AgNPs with biocompatibility 
and antibacterial ability to combat infectious pathogen. These multiple properties will be suitable to apply as antibacterial coatings for medical devices. Furthermore, we proposed the casein-AgNPs with biocompatibility and antibacterial ability to combat infectious pathogens. The casein-AgNPs would be the suitable application immobilized on nylon and silk fibers. These modified polymeric materials with antibacterial properties may have potential to be applied as antibacterial textile [18]. Moreover, the casein-AgNPs are also suitable for application as antibacterial coatings for medical devices, such as urinary catheters and nasogastric tubes.

\section{Materials and Methods}

\subsection{Materials}

Pluronic F-127 was obtained from BASF Inc. (Ludwigshafen am Rhein, Germany), TEOS (98.0\% purity) from ACROS Organics (Trenton, NJ, USA), calcium nitrate tetrahydrate (98.5\% purity) from SHOWA (Ibaraki Prefecture, Japan), triethyl phosphate (98.0\% purity) from FLUKA (Asheville, NC, USA), silver nitrate (99.8\% purity) from SHOWA (Ibaraki Prefecture, Japan) and nitric acid (99.5\% purity) from SHOWA (Ibaraki Prefecture, Japan). Tigecycline $\left(\right.$ Tygaci $^{\circledR}$ ) was purchased from Wyeth Pharmaceuticals Inc. (Collegeville, PA, USA). A. baumannii (ATCC BAA-747) was used for the antibacterial assay, was provided by the American Type Culture Collection (Manassas, VA, USA).

\subsection{Synthesis of the SSCP}

The mesoporous bioactive glass comprising $80 \mathrm{SiO}_{2}-15 \mathrm{CaO}-5 \mathrm{P}_{2} \mathrm{O}_{5}-1 \mathrm{Ag}_{2} \mathrm{O}$ was synthesized by the EISA (evaporation-induced self-assembly) method $[19,20]$. During the synthesis, 7 g non-surfactant Pluronic F127 (BASF, Ludwigshafen am Rhein, Germany) was used as the structure-directing agent, and the precursors including $6.7 \mathrm{~g}$ tetraethyl orthosilicate, TEOS (ACROS, Trenton, NJ, USA), $0.73 \mathrm{~g}$ triethyl phosphate, TEP (FLUKA, Asheville, NC, USA), $1.4 \mathrm{~g}$ calcium nitratetetrahydrate, $\mathrm{Ca}\left(\mathrm{NO}_{3}\right)_{2} \cdot 4 \mathrm{H}_{2} \mathrm{O}$ (SHOWA, Ibaraki Prefecture, Japan) and $0.13 \mathrm{~g}$ silver nitrate $\left(\mathrm{AgNO}_{3}\right.$, SHOWA, Ibaraki Prefecture, Japan) were used. The above substances were dissolved in ethanol with $2 \mathrm{M} \mathrm{HNO}_{3}\left(\mathrm{SHOWA}_{\text {, }}\right.$ Ibaraki Prefecture, Japan) and stirred at room temperature for $24 \mathrm{~h}$ to form a sol. We further immersed polyurethane foams (PUF) in the sol, which was then subjected to compression and release twice. Then, the PUF-coated sol was dried at $100{ }^{\circ} \mathrm{C}$ for $24 \mathrm{~h}$ as the aging process. Afterwards, the PUF was heated for $2 \mathrm{~h}$ at $600^{\circ} \mathrm{C}$ with a constant heating rate of $10^{\circ} \mathrm{C} / \mathrm{min}$ to remove the surfactants. Consequently, the SSCP powders were produced.

\subsection{Synthesis of Casein/Arginine-AgNPs Reagent}

The solid compositions of the SSCP powders immersed with $20 \mathrm{mg} / \mathrm{mL}$ Tryptic Soy Broth medium (containing casein and arginine solution, as a ratio 1:1) at $150 \mathrm{rpm}$ for $24 \mathrm{~h}$. Then, The SSCP powder were extracted by $0.22 \mu \mathrm{m}$ syringe filter and the suspension was collected as casein/arginine-AgNPs.

\subsection{Characterization of Casein/Arginine-AgNPs}

The casein/arginine-AgNPs reagents were measured by a DU730 UV-visible spectrometer (Beckman coulter, Brea, CA, USA) and the absorbance recorded in a 200-700 nm range of wavelengths. To characterize the structure morphology of casein/arginine-AgNP reagents, we obtained transmission electron microscopy (TEM) images to observe its dispersed solution using a JEM-2100 transmission electron microscope (JEOL, Tokyo, Japan) equipped with a $\mathrm{LaB}_{6}$ gun at $120 \mathrm{kV}$. The size and size distribution of the AgNPs were measured with at least 30 particles to obtain representative data.

\subsection{In Vitro Antibacterial Test}

\subsubsection{Bacteria Culture and Conservation}

The tested strain, Acinetobacter baumannii Bouvet and Grimont (ATCC ${ }^{\circledR}$ BAA-747 ${ }^{\mathrm{TM}}$ ) was obtained from the American Type Culture Collection (ATCC) (Manassas, VA, USA). 
According to the Bioresource Collection and Research Center (BCRC), Hsinchu, Taiwan instructions, to revive the freeze-dried A. baumannii, we used $6 \mathrm{~mL}$ trypticase soy broth (TSB) medium to rehydrate the pellet, and then mix the entire suspension. Then, $10 \mu \mathrm{L}$ suspension was dropped on trypticase soy sgar (TSA) to cultivate at $37^{\circ} \mathrm{C}$ for $24 \mathrm{~h}$ in an oxygenic environment. After $24 \mathrm{~h}$, by the streak-plate method, the forming colony on TSA plate would move to TSB medium and mixed with glycerol stock to preserve at $-80{ }^{\circ} \mathrm{C}$ freezer for conservation the bacteria.

\subsubsection{Time-Kill Kinetic Assay}

Determination of Minimal Inhibitory Concentration (MIC)

A time-kill kinetic assay was carried out using the microtiter plate method as previously described. Two treatment samples (casein/arginine-AgNPs and tigecycline) were measured against $A$. baumannii. A $10 \mu \mathrm{L}$ bacterial suspension was added to the corresponding wells of a 96-flat-bottom-well microtiter plate at a final concentration of $5 \times 10^{5}$ to $10^{6} \mathrm{CFU} / \mathrm{mL}$ (from a $0.5 \mathrm{McFarland}\left(\approx 10^{8} \mathrm{CFU} / \mathrm{mL}\right.$ ) stock) and the corresponding concentrations of either $100 \mu \mathrm{L}$ of casein/arginine-AgNPs $(0.16-20 \mathrm{mg} / \mathrm{mL}$ in 2-fold dilutions) or $100 \mu \mathrm{L}$ of tigecycline $(0.16-10 \mu \mathrm{g} / \mathrm{mL}$ in 2-fold dilutions) in a final volume of $210 \mu \mathrm{L}$ per well. Then, we used a spectrophotometer (Tecan, Mannedorf, Switzerland) to observe the bacterial growth kinetics of the optical density at $600 \mathrm{~nm}$ every hour (up to $24 \mathrm{~h}$ ) at $37^{\circ} \mathrm{C}$. Every interval before testing, the plate would be shaken for $3 \mathrm{~s}$. The plates were sealed during the whole experiment. A sterilized condensation water was used in the incubator to maintain humidity. The MIC was identified as the minimum concentration that showed no visible growth after $24 \mathrm{~h}$. The measurements were performed against $A$. baumannii in triplicates.

\section{Determination of Minimal Bactericidal Concentration (MBC)}

Determination of $\mathrm{MBC}$ was measured by colony counting of the cultures corresponding to no visible growth in the microdilution experiments described above. In the testing process, the suspension tested by the above microdilution measurement, would then streak $100 \mu \mathrm{L}$ suspension to fresh TSA by sterile swabs and incubated at $37^{\circ} \mathrm{C}$ for an additional $24 \mathrm{~h}$. MBC was considered to be the minimal concentration of antibacterial agent that reduces initial concentration of bacteria in the culture to less than $0.1 \%$, and did not form a single bacterial colony on the TSA medium.

\section{Checkerboard Assay}

The impact on the combination of casein/arginine-AgNPs and tigecycline was determined by broth microdilution assay in checkerboard testing as previously described [29]. The combination of casein/arginine-AgNPs and tigecycline diluted 2-fold in a 96-well microplate. The solutions containing $100 \mu \mathrm{L}$ of casein/arginine-AgNPs $(0.16-20 \mathrm{mg} / \mathrm{mL}$ in 2-fold dilutions) in the raw and $100 \mu \mathrm{L}$ of tigecycline $(0.16-10 \mu \mathrm{g} / \mathrm{mL}$ in 2-fold dilutions) in a final volume of $200 \mu \mathrm{L}$ per well. The A. baumannii bacteria were suspended in tryptic soy broth (TSB) medium and adjusted to $0.5 \mathrm{McFarland}$ suspension, which corresponds to $1 \times 10^{8}$ colony-forming units $/ \mathrm{mL}(\mathrm{CFU} / \mathrm{mL})$. Then, the $A$. baumannii suspension was added to the combination solution to a final concentration of $5 \times 10^{5} \mathrm{CFU} / \mathrm{mL}$ and cultured at $37^{\circ} \mathrm{C}$ for $24 \mathrm{~h}$. The MIC was defined as the minimum concentration that resulted in no visible growth after $24 \mathrm{~h}$. The optical density at $600 \mathrm{~nm}$ of the solutions was measured to confirm their MIC using a spectrophotometer (Tecan, Mannedorf, Switzerland). All experiments were done in triplicates. Furthermore, the interaction of two antibacterial agents was analyzed by the combination index (CI), according to Chou et al. [30], using the following equation:

$$
\mathrm{CI}=\left(\mathrm{D} 1 / \mathrm{Df}_{1}\right)+\left(\mathrm{D} 2 / \mathrm{Df}_{2}\right)+\left(\mathrm{D} 1 \times \mathrm{D} 2 / \mathrm{Df}_{1} \times \mathrm{Df}_{2}\right)
$$

where D1 and D2 are the MICs of each antibacterial agent in combination (in a single well), and $\mathrm{Df}_{1}$ and $\mathrm{Df}_{2}$ are the MICs of each antibacterial agent individually. The CI values of 
two antibacterial agents were defined as synergism $(\mathrm{CI}<1)$, additive effect $(\mathrm{CI}=1)$ and antagonism $(\mathrm{CI}>1)$ [31].

\subsection{Statistical Analysis of Data}

Experiment data were presented as mean \pm standard deviation. Results were statistically compared by the one-way Analysis of Variance (ANOVA) test. The statistical difference was considered to be significant when the $p<0.05$.

\section{Results and Discussion}

\subsection{Nanomaterial Characteristics}

In this study, we proposed a new colloid system, casein-AgNPs (colloid type), based on our previous work, SSCP (powder type) [29,32]. Different forms of silver between caseinAgNPs, casein/arginine-AgNPs, and arginine-AgNPs are shown in Figure 1. The spectra of arginine-AgNPs, the absorption bands located between 200 and $230 \mathrm{~nm}$ for materials containing $\mathrm{Ag}_{2} \mathrm{O}$, is due to the $4 \mathrm{~d}^{10}$ to $4 \mathrm{~d}^{9} 5 \mathrm{~s}^{1}$ transition of the $\mathrm{Ag}^{+}$ions [22]. In contrast, the spectra of casein/arginine-AgNPs appeared a peak at $423 \mathrm{~nm}$ which can be assigned to silver nanoparticles. Furthermore, the spectrum of arginine presented more silver ions than larger silver nanoparticles. T Arginine has the highest affinity towards silver ions among all amino acids, which may bind at various electron rich sites, e.g., nitrogen atoms of $\alpha$-amino groups as well as guanidino side chains, in addition to carboxyl moieties at the C-terminus [33,34]. The use of casein proteins is considered to produce bio-tolerable and highly stable silver nanoparticles with a fair control over their size without using any additional reducing agent $[15,35]$. As a result, casein/arginine-AgNPs would form stable silver-arginine complexes.

To characterize the morphology of AgNPs of casein-AgNPs, they were confirmed by TEM images shown in Figure 2. The size and size distribution of the AgNPs were measured with at least 30 particles to obtain representative data, shown in Table 1. In Figure 2a, the TEM images revealed casein-AgNPs dispersed homogeneously, and the AgNPs presented average size of $2.9 \mathrm{~nm}$. In contrast, in Figure 2b, casein/arginine-AgNPs have larger spherical sizes ranging from 10.3 to $24.2 \mathrm{~nm}$, and the average size was $17.0 \mathrm{~nm}$ and no aggregation of AgNPs was observed inside the casein matrix. Moreover, in Figure 2c, casein/arginin-AgNPs revealed the polycrystalline structure of AgNPs. The TEM images were in close agreement with the spectra obtained using UV-visible spectroscopy, indicating the formation of fairly uniform silver nanoparticles under optimum conditions. Moreover, the TEM image and average particle sizes of casein/arginine-AgNPs (after 3 months) are presented in Figure 2d and Table 1 to confirm the stability of synthesized AgNPs. The casein/arginine-AgNPs dispersed as spheres homogeneously and their particle sizes ranged from 8.6 to $30.8 \mathrm{~nm}$ and the average size was $17.2 \mathrm{~nm}$ using one-way ANOVA statistical analysis. There is no significant difference between AgNPs synthesized after three months.

In TEM images, we observed casein-AgNPs of average size $2.9 \mathrm{~nm}$ and casein/arginineAgNPs of average size $17.0 \mathrm{~nm}$. To explain the AgNPs formation process, the model of recognition-reduction-limited nucleation was used [36]. Moreover, proteins inspired silver ions from SSCP matrix. Then, the silver nuclei and proteins combined, causing growth by more reduction of silver ions and accumulation on these nuclei. Additionally, the protein linkage and lots of biomolecules suspended in the reaction solutions would improve stable spherical AgNPs formation. With sufficient aging time, large-sized AgNPs were obtained, and the crystalline phase transferred from polycrystalline to single crystalline by Ostwald ripening. Casein presented a stabilizing effect on the AgNPs, and arginine possessed high affinity towards metals for larger particle formation. 


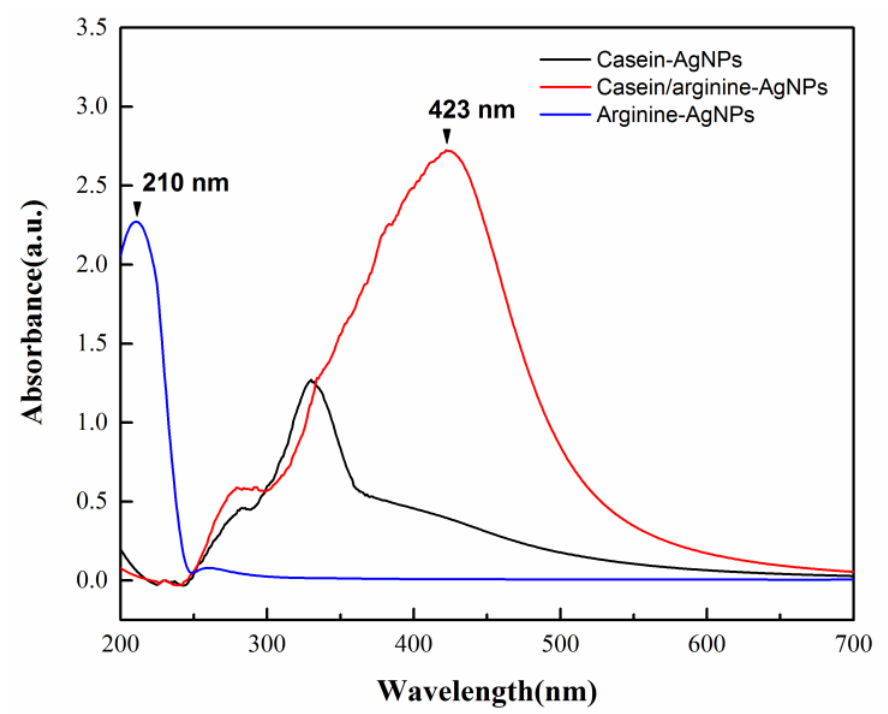

Figure 1. UV-visible spectra of casein, casein/arginine-AgNPs, and arginine-AgNPs.

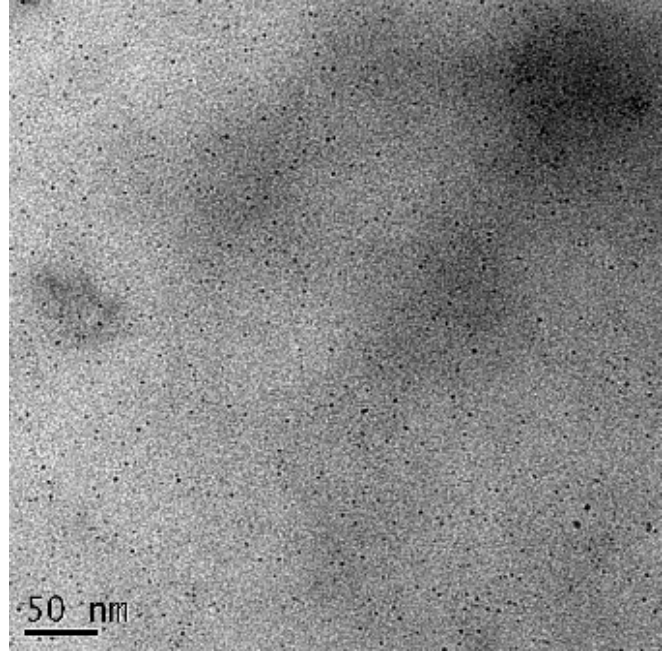

(a)

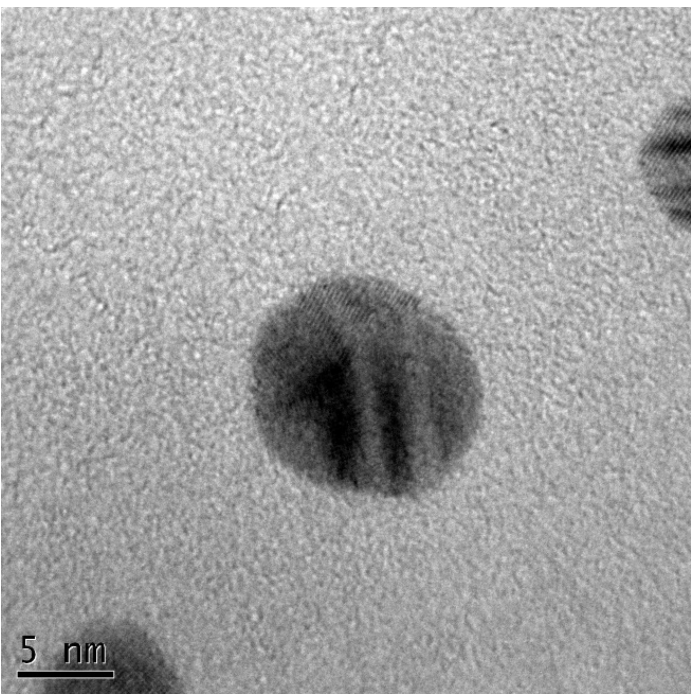

(c)

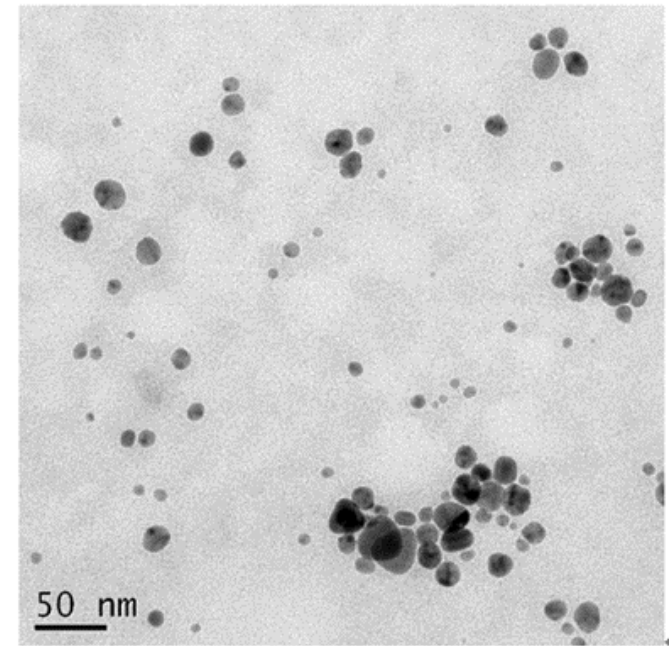

(b)

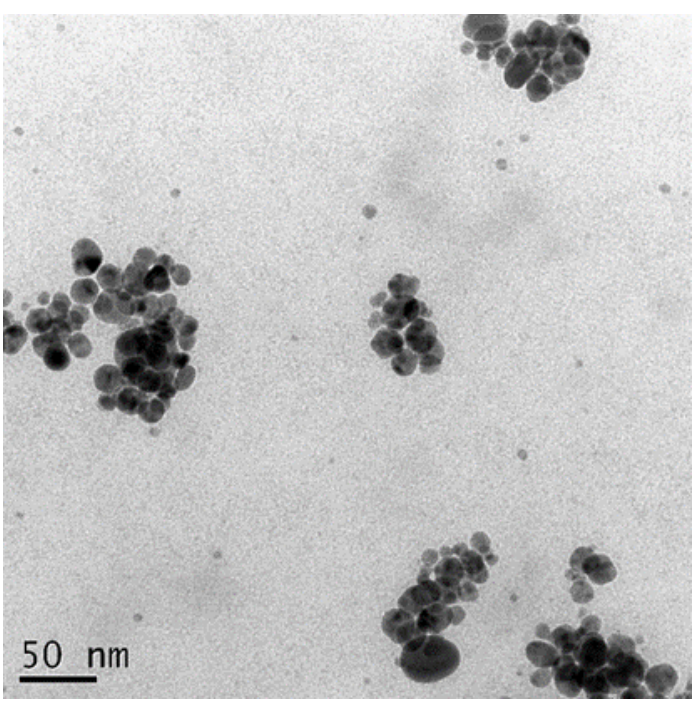

(d)

Figure 2. TEM images of (a) Casein-AgNPs; (b,c) Casein/arginine-AgNPs and (d) Casein/arginine-AgNPs (after 3 months). 
Table 1. Size distribution of AgNPs $(n=30) .(p<0.05)$

\begin{tabular}{ccc}
\hline Silver Reagent & Size Distribution of AgNPs (nm) & Average Size of AgNPs (nm) \\
\hline Casein-AgNPs & $1.7-4.6$ & $2.9 \pm 0.8$ \\
\hline $\begin{array}{c}\text { Casein/arginine-AgNPs } \\
\text { (after 3 months) }\end{array}$ & $10.3-24.2$ & $17.0 \pm 4.5$ \\
\hline \begin{tabular}{c} 
Casein arginine-AgNPs \\
\hline
\end{tabular} & $8.6-30.8$ & $17.2 \pm 4.2$ \\
\hline
\end{tabular}

\subsection{Antibacterial Activity of Casein/Arginine-AgNPs}

Antibacterial effects depend on the composition, size, shape, and synthesis method of each AgNPs. In our previous study, we provided the mesoporous SSCP to restrict AgNPs in small sizes to avoid agglomeration. Then, we used casein to inspire AgNP from SSCP and stabilize AgNPs. To examine the antimicrobial activity of casein/arginine-AgNPs, alone and in combination with tigecycline, antibacterial susceptibility measurements were conducted against A. baumannii. As shown in Figure 3, casein/arginine-AgNPs showed antibacterial activity against $A$. baumannii with MIC values of $1.25 \mathrm{mg} / \mathrm{mL}$. For the $A$. baumannii growth kinetics, the treatment with casein/arginine-AgNPs after $10 \mathrm{~h}$, less than $0.63 \mathrm{mg} / \mathrm{mL}$, and viable bacterial growth was observed. According to the colony-forming results in Figure 4, the MBC value of casein/arginine-AgNPs is $1.25 \mathrm{mg} / \mathrm{mL}$, which agrees with the MIC.

As shown in Figure 3, casein/arginine-AgNPs showed antibacterial activity against A. baumannii with MIC values of $1.25 \mathrm{mg} / \mathrm{mL}$. For the time-kill kinetic curves, after $10 \mathrm{~h}$ of treatment with casein/arginine-AgNPs less than $0.63 \mathrm{mg} / \mathrm{mL}$, viable bacterial growth was observed. Moreover, AgNPs were more effective against Gram-negative bacteria than against Gram-positive bacteria, as previously described, due to the membrane layer of the bacterial structure.

Tigecycline showed antibacterial ability against $A$. baumannii with MIC values of $2.5 \mu \mathrm{g} / \mathrm{mL}$ and finish with Figure 4. Moreover, the $2 \mathrm{MIC}(5 \mu \mathrm{g} / \mathrm{mL})$ and $4 \mathrm{MIC}(10 \mu \mathrm{g} / \mathrm{mL})$ growth kinetics of tigecycline represented a slight increase in optical density (OD) values at a wavelength of $600 \mathrm{~nm}$. In contrast, the $1 / 2 \mathrm{MIC}(0.63 \mu \mathrm{g} / \mathrm{mL})$ and $1 / 4 \mathrm{MIC}(0.31 \mu \mathrm{g} / \mathrm{mL})$ growth kinetics of casein/arginine-AgNPs experienced a significant increase.

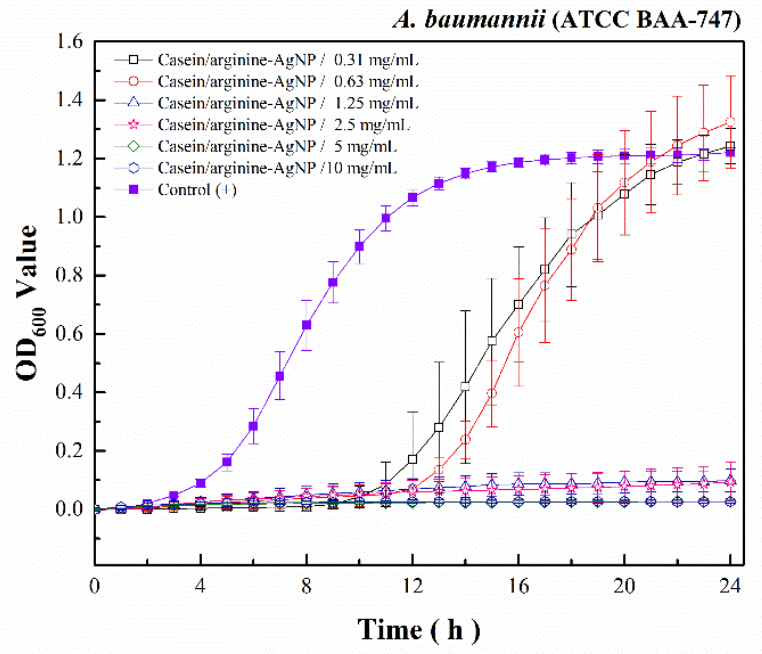

Figure 3. The A. baumannii growth kinetic results of casein/arginine-AgNPs. 


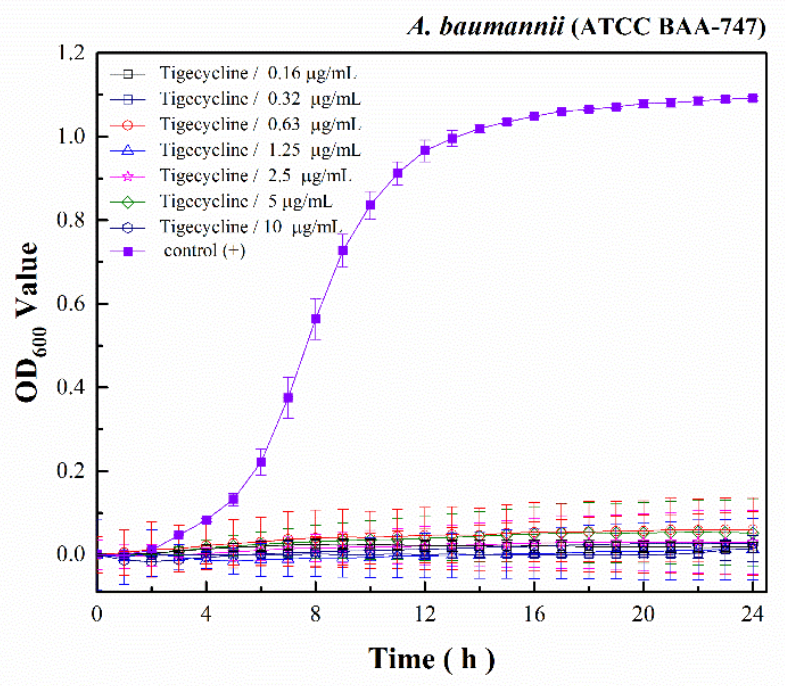

Figure 4. The A. baumannii growth kinetics of tigecycline.

\subsection{Synergy Effect of the Combination of Tigecycline and Casein/Arginine-AgNPs}

The results of the checkerboard assay confirmed that there was a synergistic antibacterial effect between AgNPs and tigecycline, as shown in Table 2. According to the lowest CI values $(\mathrm{CI}=0.59)$, the result showed the best synergistic effect with casein/arginine-AgNPs at $1 / 2 \mathrm{MIC}(0.31 \mathrm{mg} / \mathrm{mL})$ and tigecycline at $1 / 16(0.16 \mu \mathrm{g} / \mathrm{mL})$. The synergistic effect was also present with the combination of casein/arginine-AgNPs at $1 / 2 \mathrm{MIC}(0.31 \mathrm{mg} / \mathrm{mL})$ and tigecycline at $1 / 4$ and $1 / 8 \mathrm{MIC}(0.63$ and $0.31 \mu \mathrm{g} / \mathrm{mL})$. Moreover, the combination of casein/arginine-AgNPs at $1 / 4 \mathrm{MIC}(0.16 \mathrm{mg} / \mathrm{mL})$ and tigecycline at $1 / 2 \mathrm{MIC}(1.25 \mu \mathrm{g} / \mathrm{mL})$ showed the synergistic effect as well.

Furthermore, as a result of the colony-forming assay in Figure 5, the synergistic combination provided their bactericidal ability with culturing for an additional $24 \mathrm{~h}$. There is little attention paid to investigating the synergistic combination with silver to combat A. baumannii. First, the colony-forming results of casein/arginine-AgNPs with the concentration of $10,5,2.5,1.25,0.63,0.31,0.16$, and $0.08 \mathrm{mg} / \mathrm{mL}$ are presented in $\mathrm{A} 1$, B1, C1, D1, E1, F1, G1, and H1. We observed a small number of bacteria in $0.63 \mathrm{mg} / \mathrm{mL}$ (E1) and $0.31 \mathrm{mg} / \mathrm{mL}$ (F1), indicating gradual bacterial inhibition. This is caused by the antibacterial mechanism of silver ions decreasing bacteria proliferation and increasing apoptosis in A. baumannii [32].

On the other hand, the bactericidal results of tigecycline alone with concentrations of $10,5,2.5,1.25,0.63,0.31$, and $0.16 \mu \mathrm{g} / \mathrm{mL}$ are shown in I2, I3, I4, I5, I6, I7, and I8. The bacterial colony results show complete inhibition, rather than gradual inhibition. In this study, we integrated the effects of AgNPs and tigecycline by determining bacterial growth kinetics at $24 \mathrm{~h}$ and performing a colony-forming assay at $48 \mathrm{~h}$. However, the combinations for bacterial colonization assay were less effective to kill A. baumannii completely, due to its Gram-negative structure. The Gram-negative bacteria is composed of a thin peptidoglycan layer sandwiched between an inner cytoplasmic cell membrane and a bacterial outer membrane [37].

As a result, we integrated the synergistic antibacterial ability of casein/arginineAgNPs at $1 / 2$ MIC $(0.31 \mathrm{mg} / \mathrm{mL})$ and tigecycline at $1 / 16(0.16 \mu \mathrm{g} / \mathrm{mL})$ in combination. We proposed the combination of AgNP and tigecycline providing two different antibacterial mechanisms to increase its efficiency. AgNPs and tigecycline also showed different degrees of antibacterial activity in relation to their material properties [37]. First, AgNPs would be oxidized as partial oxidation to form $\mathrm{Ag}_{2} \mathrm{O}$ and then release silver ions [38]. Silver ions would be incorporated into bacterial cell membranes and bind to membrane proteins to block their respiratory system [39]. On the other hand, the antibacterial mechanism of tigecycline is due to its glycylcycline structure interacting with the bacterial $30 \mathrm{~S}$ ribosome subunit, blocking the entry of transfer RNA to block protein synthesis. Meanwhile, 
chloramphenicol and kanamycin also show a similar mechanism of inhibiting bacterial protein synthesis. Pajares-Chamorro et al. provided the synergistic effect of similar silvercontaining materials combined with antibiotics, although their exact combinatorial relationship was not extensively discussed. In other previous studies, a synergistic effect was shown as AgNPs combining with common antibiotics, including gentamycin, amoxicillin, linezolid and vancomycin, against pathogens [25,39].

Based on the results of synergistic antibacterial ability, the combination of caseinAgNPs and tigecycline could suppress the growth of A. baumannii, which should be further confirmed in animal models and clinical trials. Moreover, we supposed the ecofriendly approach to prepare AgNPs with efficient antibacterial ability would be suitably applied as antibacterial fibers such as wound dressing and antibacterial coatings for medical devices, such as urinary catheters and nasogastric tubes.

Table 2. MIC of different antibacterial agents for A. baumannii and the calculated CI values.

\begin{tabular}{cccc}
\hline Sample Name & MIC of Tigecycline $(\mu \mathrm{g} / \mathbf{m L})$ & MIC of Casein/Arginine-AgNPs $(\mathbf{m g} / \mathbf{m L})$ & CI \\
\hline & 0.16 & 1.25 & 0.88 \\
Casein/arginine-AgNPs & 0.31 & 0.63 & 0.88 \\
and Tigecycline & 0.31 & 0.31 & 0.69 \\
& 0.31 & 0.16 & 0.59 \\
\hline
\end{tabular}

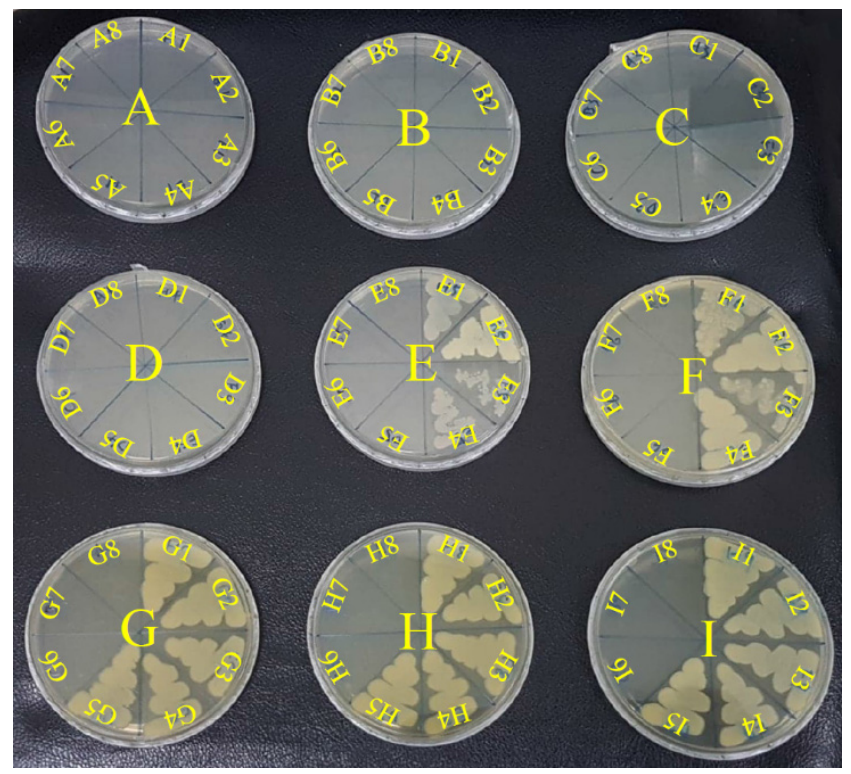

Figure 5. The colony-forming capacity results of the combination of casein/arginine-AgNPs and tigecycline. The combination of A series (casein/arginine-AgNPs $=10 \mathrm{mg} / \mathrm{mL}$; A1-A8 Tigecycline $=0,0.16,0.31,0.63,1.25,2.5,5,10 \mu \mathrm{g} / \mathrm{mL}$ ); B series (casein/arginine-AgNPs $=5 \mathrm{mg} / \mathrm{mL}$; B1-B8 Tigecycline $=0,0.16,0.31,0.63,1.25,2.5,5,10 \mu \mathrm{g} / \mathrm{mL}$ ); C series (casein/arginine-AgNPs $=2.5 \mathrm{mg} / \mathrm{mL} ; \mathrm{C} 1-\mathrm{C} 8$ Tigecycline $=0,0.16,0.31,0.63,1.25,2.5,5,10 \mu \mathrm{g} / \mathrm{mL}$ ); D series (casein/arginineAgNPs = $1.25 \mathrm{mg} / \mathrm{mL}$; D1-D8 Tigecycline = 0, 0.16, 0.31, 0.63, 1.25, 2.5, 5, $10 \mu \mathrm{g} / \mathrm{mL}$ ); E series (casein/arginine-AgNPs $=0.63 \mathrm{mg} / \mathrm{mL} ; \mathrm{E} 1-\mathrm{E} 8$ Tigecycline $=0,0.16,0.31,0.63,1.25,2.5,5,10 \mu \mathrm{g} / \mathrm{mL}$ ); F series (casein/arginine-AgNPs $=0.31 \mathrm{mg} / \mathrm{mL} ; \mathrm{F} 1-\mathrm{F} 8$ Tigecycline $=0,0.16,0.31,0.63,1.25,2.5,5$, $10 \mu \mathrm{g} / \mathrm{mL}$ ); G series (casein/arginine-AgNPs $=0.16 \mathrm{mg} / \mathrm{mL} ; \mathrm{G} 1-\mathrm{G} 8$ Tigecycline = 0, 0.16, 0.31, 0.63, $1.25,2.5,5,10 \mu \mathrm{g} / \mathrm{mL}$ ); H series (casein/arginine-AgNPs $=0.08 \mathrm{mg} / \mathrm{mL} ; \mathrm{H} 1-\mathrm{H} 8$ Tigecycline $=0,0.16$, $0.31,0.63,1.25,2.5,5,10 \mu \mathrm{g} / \mathrm{mL}$ ); I series (casein/arginine-AgNPs $=0 \mathrm{mg} / \mathrm{mL}$; I1-I8 Tigecycline $=0$, $0.16,0.31,0.63,1.25,2.5,5,10 \mu \mathrm{g} / \mathrm{mL})$. 


\section{Conclusions}

In this study, we investigated the combination of casein/arginine-AgNPs with tigecycline as a new formulation to combat $A$. baumannii. For antibacterial material, casein and arginine would increase nucleation of AgNPs from SSCP. The average size of AgNPs in $17.0 \mathrm{~nm}$ inside the casein protein was observed by TEM image. In an in vitro antibacterial test, the MRSA time-kill kinetics showed the MIC of casein/arginine-AgNPs with $1.25 \mathrm{mg} / \mathrm{mL}$. Moreover, the combination composed with casein/arginine-AgNPs at $1 / 2 \mathrm{MIC}(0.31 \mathrm{mg} / \mathrm{mL})$ and tigecycline at $1 / 16(0.16 \mu \mathrm{g} / \mathrm{mL})$ presented the CI value $(0.59)$ for synergistic antibacterial ability by a checkerboard method. Consequently, based on the results of synergistic antibacterial ability, the combination of casein-AgNPs and tigecycline could suppress the growth of A. baumannii, which should be further confirmed in animal models and clinical trials. Moreover, we suppose the materials as antibacterial agent could be applied as antibacterial coatings for medical devices.

Author Contributions: Conceptualization, Y.-H.C., W.-H.W., S.-H.L., C.-S.C. and C.-J.S.; methodology, Y.-H.C., W.-H.W., S.-H.L., Y.-T.Y.-W., C.-S.C. and C.-J.S.; validation, S.-H.L. and C.-J.S.; formal analysis, Y.-H.C., Y.-T.Y.-W. and S.-H.L.; investigation, Y.-H.C.; resources, C.-J.S.; data curation, Y.-H.C., W.-H.W. and Y.-T.Y.-W.; writing-original draft preparation, Y.-H.C., W.-H.W., S.-H.L. and Y.-T.Y.-W.; writingreview and editing, C.-S.C. and C.-J.S.; visualization, S.-H.L., S.-P.T. and C.-S.C.; supervision, C.-J.S.; project administration, C.-S.C. and C.-J.S.; funding acquisition, W.-H.W. and C.-J.S. The authors, Y.-H.C. and W.-H.W. contributed equally to this work. All authors have read and agreed to the published version of the manuscript.

Funding: This research was funded by the Research Project of Ministry of Science and Technology, Taiwan (MOST 107-2221-E-037-001-MY3, MOST 109-2314-B-384-001), the Special Research Project of Kaohsiung Medical University, Taiwan (KMU-TC108A03-7), the Research Project of Chi Mei Medical Center and Kaohsiung Medical University Research Foundation, Taiwan (109CM-KMU-005), the Special Research Project of Chi Mei Medical Centre, Taiwan (CMFHR 10888) and the Research Cooperation Project of Kaohsiung Medical University and Changhua Christian Hospital, Changhua Christian Medical Foundation, Taiwan (108-CCH-KMU-007).

Institutional Review Board Statement: Not applicable.

Informed Consent Statement: Not applicable.

Data Availability Statement: The data presented in this study are available on request from the corresponding author.

Acknowledgments: The authors acknowledge support of grants from the Research Project of Ministry of Science and Technology, Kaohsiung Medical University, Chi Mei Medical Center, and Changhua Christian Hospital, Changhua Christian Medical Foundation, Taiwan.

Conflicts of Interest: The authors declare no conflict of interest.

\section{References}

1. Deng, H.; McShan, D.; Zhang, Y.; Sinha, S.S.; Arslan, Z.; Ray, P.C.; Yu, H. Mechanistic Study of the Synergistic Antibacterial Activity of Combined Silver Nanoparticles and Common Antibiotics. Environ. Sci. Technol. 2016, 50, 8840-8848. [CrossRef] [PubMed]

2. Tseng, S.P.; Hung, W.C.; Huang, C.Y.; Lin, Y.S.; Chan, M.Y.; Lu, P.L.; Lin, L.; Sheu, J.H. 5-Episinuleptolide Decreases the Expression of the Extracellular Matrix in Early Biofilm Formation of Multi-Drug Resistant Acinetobacter baumannii. Mar. Drugs 2016, 14, 143. [CrossRef]

3. Krausz, A.E.; Adler, B.L.; Cabral, V.; Navati, M.; Doerner, J.; Charafeddine, R.A.; Chandra, D.; Liang, H.; Gunther, L.; Clendaniel, A.; et al. Curcumin-encapsulated nanoparticles as innovative antimicrobial and wound healing agent. Nanomedicine 2015, 11, 195-206. [CrossRef] [PubMed]

4. Towner, K.J. Acinetobacter: An old friend, but a new enemy. J. Hosp. Infect. 2009, 73, 355-363. [CrossRef]

5. Mussi, M.A.; Limansky, A.S.; Viale, A.M. Acquisition of resistance to carbapenems in multidrug-resistant clinical strains of Acinetobacter baumannii: Natural insertional inactivation of a gene encoding a member of a novel family of beta-barrel outer membrane proteins. Antimicrob. Agents Chemother. 2005, 49, 1432-1440. [CrossRef]

6. Leekha, S.; Terrell, C.L.; Edson, R.S. General principles of antimicrobial therapy. Mayo Clin. Proc. 2011, 86, 156-167. [CrossRef] 
7. Garnacho-Montero, J.; Timsit, J.F. Managing Acinetobacter baumannii infections. Curr. Opin. Infect. Dis. 2018, 32, 69-76. [CrossRef] [PubMed]

8. Shen, F.; Han, Q.; Xie, D.; Fang, M.; Zeng, H.; Deng, Y. Efficacy and safety of tigecycline for the treatment of severe infectious diseases: An updated meta-analysis of RCTs. Int. J. Infect. Dis. 2015, 39, 25-33. [CrossRef]

9. Tasina, E.; Haidich, A.-B.; Kokkali, S.; Arvanitidou, M. Efficacy and safety of tigecycline for the treatment of infectious diseases: A meta-analysis. Lancet Infect. Dis. 2011, 11, 834-844. [CrossRef]

10. Cai, Y.; Wang, R.; Liang, B.; Bai, N.; Liu, Y. Systematic review and meta-analysis of the effectiveness and safety of tigecycline for treatment of infectious disease. Antimicrob. Agents Chemother. 2011, 55, 1162-1172. [CrossRef]

11. Mourino, V.; Cattalini, J.P.; Boccaccini, A.R. Metallic ions as therapeutic agents in tissue engineering scaffolds: An overview of their biological applications and strategies for new developments. J. R. Soc. Interface 2012, 9, 401-419. [CrossRef] [PubMed]

12. Hoppe, A.; Mourino, V.; Boccaccini, A.R. Therapeutic inorganic ions in bioactive glasses to enhance bone formation and beyond. Biomater. Sci. 2013, 1, 254-256. [CrossRef]

13. Chernousova, S.; Epple, M. Silver as antibacterial agent: Ion, nanoparticle, and metal. Angew. Chem. Int. Ed. 2013, 52, 1636-1653. [CrossRef]

14. Hebbalalu, D.; Lalley, J.; Nadagouda, M.N.; Varma, R.S. Greener Techniques for the Synthesis of Silver Nanoparticles Using Plant Extracts, Enzymes, Bacteria, Biodegradable Polymers, and Microwaves. ACS Sustain. Chem. Eng. 2013, 1, 703-712. [CrossRef]

15. Ashraf, S.; Abbasi, A.Z.; Pfeiffer, C.; Hussain, S.Z.; Khalid, Z.M.; Gil, P.R.; Parak, W.J.; Hussain, I. Protein-mediated synthesis, $\mathrm{pH}$-induced reversible agglomeration, toxicity and cellular interaction of silver nanoparticles. Colloids Surf. B Biointerfaces 2013, 102, 511-518. [CrossRef]

16. Ullah, N.; Li, D.; Xiaodong, C.; Yasin, S.; Umair, M.M.; Van Eede, S.S.; Wei, Q. Photo-Irradiation Based Biosynthesis of Silver Nanoparticles by Using an Ever Green Shrub and Its Antibacterial Study. Dig. J. Nanomater. Biostruct. 2015, $10,95-106$.

17. Saratale, R.G.; Saratale, G.D.; Ghodake, G.; Cho, S.K.; Kadam, A.; Kumar, G.; Jeon, B.H.; Pant, D.; Bhatnagar, A.; Shin, H.S. Wheat straw extracted lignin in silver nanoparticles synthesis: Expanding its prophecy towards antineoplastic potency and hydrogen peroxide sensing ability. Int. J. Biol. Macromol. 2019, 128, 391-400. [CrossRef]

18. Memon, H.; Wang, H.; Yasin, S.; Halepoto, A. Influence of Incorporating Silver Nanoparticles in Protease Treatment on Fiber Friction, Antistatic, and Antibacterial Properties of Wool Fibers. J. Chem. 2018, 2018, 4845687. [CrossRef]

19. Saratale, G.D.; Saratale, R.G.; Kim, D.S.; Kim, D.; Shin, H.S. Exploiting Fruit Waste Grape Pomace for Silver Nanoparticles Synthesis, Assessing Their Antioxidant, Antidiabetic Potential and Antibacterial Activity against Human Pathogens: A Novel Approach. Nanomaterials 2020, 10, 1457. [CrossRef]

20. Saratale, R.G.; Shin, H.S.; Kumar, G.; Benelli, G.; Ghodake, G.S.; Jiang, Y.Y.; Kim, D.S.; Saratale, G.D. Exploiting fruit byproducts for eco-friendly nanosynthesis: Citrus x clementina peel extract mediated fabrication of silver nanoparticles with high efficacy against microbial pathogens and rat glial tumor C6 cells. Environ. Sci. Pollut. Res. 2018, 25, 10250-10263. [CrossRef]

21. Ullah, N.; Yasin, S.; Abro, Z.; Liu, L.; Wei, Q.F. Mechanically Robust and Antimicrobial Cotton Fibers Loaded with Silver Nanoparticles: Synthesized via Chinese Holly Plant Leaves. Int. J. Text. Sci. 2014, 3, 1-5. [CrossRef]

22. Jiang, B.; Wang, X.J.; Wang, L.L.; Wu, S.; Li, D.M.; Liu, C.H.; Feng, Z.B. Fabrication and Characterization of a Microemulsion Stabilized by Integrated Phosvitin and Gallic Acid. J. Agric. Food Chem. 2020, 68, 5437-5447. [CrossRef] [PubMed]

23. Wang, Q.N.; Liu, W.H.; Tian, B.; Li, D.M.; Liu, C.H.; Jiang, B.; Feng, Z.B. Preparation and Characterization of Coating Based on Protein Nanofibers and Polyphenol and Application for Salted Duck Egg Yolks. Foods 2020, 9, 449. [CrossRef]

24. Zhang, Y.; Liang, S.; Zhang, J.S.; Chi, Y.J.; Tian, B.; Li, L.L.; Jiang, B.; Li, D.M.; Feng, Z.B.; Liu, C.H. Preparation of whey protein isolate nanofibrils by microwave heating and its application as carriers of lipophilic bioactive substances. LWT-Food Sci. Technol. 2020, 125, 109213. [CrossRef]

25. Li, P.; Li, J.; Wu, C.; Wu, Q.; Li, J. Synergistic antibacterial effects of $\beta$-lactam antibiotic combined with silver nanoparticles. Nanotechnology 2005, 16, 1912-1917. [CrossRef]

26. Fayaz, A.M.; Balaji, K.; Girilal, M.; Yadav, R.; Kalaichelvan, P.T.; Venketesan, R. Biogenic synthesis of silver nanoparticles and their synergistic effect with antibiotics: A study against gram-positive and gram-negative bacteria. Nanomedicine 2010, 6, 103-109. [CrossRef]

27. Pajares-Chamorro, N.; Shook, J.; Hammer, N.D.; Chatzistavrou, X. Resurrection of antibiotics that methicillin-resistant Staphylococcus aureus resists by silver-doped bioactive glass-ceramic microparticles. Acta Biomater. 2019, 96, 537-546. [CrossRef]

28. Yahav, D.; Lador, A.; Paul, M.; Leibovici, L. Efficacy and safety of tigecycline: A systematic review and meta-analysis. J. Antimicrob. Chemother. 2011, 66, 1963-1971. [CrossRef]

29. Chien, C.-S.; Lin, C.-J.; Ko, C.-J.; Tseng, S.-P.; Shih, C.-J. Antibacterial activity of silver nanoparticles (AgNP) confined to mesostructured silica against methicillin-resistant Staphylococcus aureus (MRSA). J. Alloys Compd. 2018, 747, 1-7. [CrossRef]

30. Chou, T.C. Drug combination studies and their synergy quantification using the Chou-Talalay method. Cancer Res. 2010, 70, 440-446. [CrossRef]

31. Wang, Y.; Ding, X.L.; Chen, Y.; Guo, M.Q.; Zhang, Y.; Guo, X.K.; Gu, H.C. Antibiotic-loaded, silver core-embedded mesoporous silica nanovehicles as a synergistic antibacterial agent for the treatment of drug-resistant infections. Biomaterials 2016, 101, 207-216. [CrossRef] 
32. Kung, J.-C.; Chen, Y.-J.; Chiang, Y.-C.; Lee, C.-L.; Yang-Wang, Y.-T.; Hung, C.-C.; Shih, C.-J. Antibacterial activity of silver nanoparticle (AgNP) confined mesoporous structured bioactive powder against Enterococcus faecalis infecting root canal systems. J. Non-Cryst. Solids 2018, 502, 62-70. [CrossRef]

33. Agnihotri, S.; Bajaj, G.; Mukherji, S.; Mukherji, S. Arginine-assisted immobilization of silver nanoparticles on ZnO nanorods: An enhanced and reusable antibacterial substrate without human cell cytotoxicity. Nanoscale 2015, 7, 7415-7429. [CrossRef]

34. Shoeib, T.; Siu, K.W.M.; Hopkinson, A.C. Silver ion binding energies of amino acids: Use of theory to assess the validity of experimental silver ion basicities obtained from the kinetic method. J. Phys. Chem. A 2002, 106, 6121-6128. [CrossRef]

35. Yang, T.-Y.; Hsieh, Y.-J.; Lu, P.-L.; Lin, L.; Wang, L.-C.; Wang, H.-Y.; Tsai, T.-H.; Shih, C.-J.; Tseng, S.-P. In vitro and in vivo assessments of inspired ag/80S bioactive nanocomposites against carbapenem-resistant Klebsiella pneumoniae. Mater. Sci. Eng. C 2021, 125, 112093. [CrossRef]

36. Li, S.K.; Shen, Y.H.; Xie, A.J.; Yu, X.R.; Qiu, L.G.; Zhang, L.; Zhang, Q.F. Green synthesis of silver nanoparticles using Capsicum annuum L. extract. Green Chem. 2007, 9, 852-858. [CrossRef]

37. Kusano, K.; Waterman, M.R.; Sakaguchi, M.; Omura, T.; Kagawa, N. Protein Synthesis Inhibitors and Ethanol Selectively Enhance Heterologous Expression of P450s and Related Proteins in Escherichia coli. Arch. Biochem. Biophys. 1999, 367, 129-136. [CrossRef]

38. Lok, C.-N.; Ho, C.-M.; Chen, R.; He, Q.-Y.; Yu, W.-Y.; Sun, H.; Tam, P.K.-H.; Chiu, J.-F.; Che, C.-M. Silver nanoparticles: Partial oxidation and antibacterial activities. JBIC J. Biol. Inorg. Chem. 2007, 12, 527-534. [CrossRef]

39. Akram, F.E.; El-Tayeb, T.; Abou-Aisha, K.; El-Azizi, M. A combination of silver nanoparticles and visible blue light enhances the antibacterial efficacy of ineffective antibiotics against methicillin-resistant Staphylococcus aureus (MRSA). Ann. Clin. Microbiol. Antimicrob. 2016, 15, 48. [CrossRef] 